The Canadian Journal of Higher Education, Vol. XXIII-3, 1993

La revue canadienne d'enseignement supérieur, Vol. XXIII-3, 1993

\title{
Winning Ways or Winning Weighs: Obtaining a SSHRCC Doctoral Fellowship
}

\section{G. WALL* \& J.S. FRIDERES*}

\section{Abstract}

Over the past decade there has been a dramatic increase in the number of students applying to graduate school and as the cost of education continues to escalate, more students have been applying for external funding such as SSHRCC doctoral fellowships. Over time, guidelines for assessing applications have been established by the various SSHRCC committees in order to decide which applicants will be successful. The present research identifies the qualifications of applicants which are related to obtaining a SSHRCC doctoral fellowship.

One hundred fourteen applications were randomly selected for analysis. A variety of information from the application, e.g., thesis proposal, letters of recommendation, schools attended, publications, was coded and subjected to multivariate analysis. The results show that a high degree of unanimity was evident among assessors. Referee appraisals and the rank provided by the department are important in deciding whether a student is recommended for a SSHRCC fellowship. Publications and other academic awards play a lesser but significant role in the decision-making process. The results also suggest that gender and participation in the labour force are potentially important variables in determining an applicant's success in obtaining a fellowship.

* University of Calgary 


\section{Résumé}

Au cours de la dernière décennie, le nombre d'étudiants demandant leur admission à des programmes d'études post-universitaires a augmenté considérablement et, comme les frais de scolarité ont également continué à croître, de plus en plus d'étudiants font des demandes de fonds externes comme les bourses doctorales du Conseil de recherches en sciences humaines du Canada (CRSHC). Avec le temps, les divers comités du CRSHC ont établi des directives pour évaluer les demandes et choisir les récipiendaires. La présente recherche analyse les qualifications des candidats qui sont reliées à l'obtention d'une bourse doctorale du CRSHC.

Cent quatorze demandes ont été choisies au hasard en vue de l'analyse. Une variété de renseignements apparaissant sur les formulaires de demande de bourses, c'est-à-dire la proposition de thèse, les lettres de recommandation, les écoles fréquentées, les publications, ont été codés et soumis à une analyse multivariée. Les résultats ont indiqué qu'il existe un haut niveau d'unanimité chez les évaluateurs. Les résultats montrent que les évaluations des juges et le rang accordé par le département sont des facteurs importants pour décider si un étudiant est recommandé ou non pour une bourse du CRSHC. Les publications et les autres distinctions scolaires jouent un moindre rôle, bien qu'important, dans le processus de prise de décision. Les résultats laissent aussi entendre que le sexe et la participation au marché du travail sont des variables possiblement importantes dans la détermination du succès des candidats à obtenir une bourse.

\section{Introduction}

The number of doctoral and Masters students in Canadian universities has increased substantially over the past three decades. In 1961 there were fewer than 5,000 graduate students; today there are ten times that number. The number of Ph.D.s awarded in all fields of study of study has increased from 1,400 in 1970 to double that in 1991 (Norbert et al., 1991). Social sciences graduate students represent the largest single component of students seeking a graduate degree, nearly forty percent. These figures reflect a growing competition among those who apply for financial support.

Over the past two decades, social sciences have contributed to a better understanding of our society and its institutions. The impact of social science knowledge on a number of issues, e.g., social adaptation to technological change, industrial relations, ethnic relations, criminology, has been substantial, and it continues to make both theoretical and practical contributions. At the 
international level, social science research has contributed to research on third world involvement, conflict resolution and international competition. Observers have noted that we have a need for an understanding of social change so that crises can be avoided as we enter into a new "post modern" society. The level of knowledge held by decision makers and by the public will determine the quality and effectiveness of our responses to social issues (Trent, 1984).

Graduate and professional schools are the repositories of the most complex, esoteric and potentially change-producing knowledge in any society. They allow students to build upon the intellectual curiosity created and stimulated in their undergraduate experience. As students enter graduate programs, they are able to analyze and explore complex problems as well as place what they are learning in a broader context. The major purpose of the graduate program is to produce individuals dedicated to the advancement of knowledge and trained in the art of discovery. As such, they might be viewed as preparatory grounds for young scholars being readied for the academy. Graduate schools, however, are encouraged not only to train individuals in the direct business of carrying out research, but also to ensure that even those graduate students who do not carry out research programs will think analytically, develop scholarly interests and keep up with new advancements in their field (Macdonald, 1966). This secondary goal means that the training received will help prepare students for significant aspects of their lives beyond the academy. In both cases, however, the in-depth study they receive will allow students to respond to the increasing diversity and inter-connectedness of the world now confronting them.

Over the past twenty years, our universities have become the most accessible in the world. In addition, the need for graduate training has become common place in the labour market. These factors have substantially increased the number of students wanting to enter graduate programs. Not all qualified students, however, are able to afford the cost of graduate schools. For example, regional interchange in the country has been reduced dramatically over the past ten years. In 1980, twelve percent of the students enrolled were from outside their home province; a decade later this proportion has been reduced to eight percent. One way to ensure that students are able to go on to graduate school is to provide financial incentives. To insure a continuing supply of graduate students, we have devised complex forms of scholarships for students which allow them to further their educational pursuits. Scholarships awarded to graduate students reflect the perceived significance of their research as well as the belief that they are capable of completing their proposed program of study. O'Brecht and Pihl (1991) also point out that the awarding of fellowships acknowledges the usefulness of their work to society itself (p. 48). 
Because of the paucity of funds and the high cost of obtaining a graduate degree, fewer students will be able to attend graduate schools if they are unable to receive financial support. Funding students who have the skills, intelligence and motivation to succeed, regardless of their financial resources, is not only desirable from a social equity standpoint, but also important in ensuring that the best students are able to enter graduate programs. These are the ones who will be asked to support the next generation of students as well as develop the intellectual capital of this country.

While an increasing number of students are now applying to graduate school, fewer are able to enter without financial support (Khashan, 1992). The actual number of graduate students receiving financial aid (assistantships, bursaries, fellowships) varies by discipline and university. Support for students has generally been through federal and provincial grants which allow universities to offer assistantships; however, as governments have reduced their contributions, other forms of financial support have become more important. Unfortunately, industry has not invested in graduate training and when it has invested, it has focused on medical and "hard" science programs. All this means that external fellowships (e.g., national granting agencies, philanthropic organizations) are more important to the operation of today's universities (Gumport, 1990), including the support for graduate students, and particularly those in the social sciences.

Some departments in the social sciences have taken the position that only students who are funded will be allowed to enter their programs. Others take a more "liberal" approach and admit more than they can fund and "allow the water to find its level." For example, many schools allow all qualified students to enter the first year of graduate studies (without funding) and then select only a few for funding. Thus, students who have marginal academic records are admitted without funding with the provision that if they are good, they will survive the first year of graduate school and be eligible for funding thereafter. While universities can develop strategies and programs for determining the allocation of assistantships, they are not able to set the criteria for the allocation of provincial, philanthropic or national fellowships or scholarships. In most cases, fellowships, scholarships and other awards for students are outside the control of the individual departments or universities. External adjudicating groups are put together to assess independently the merits of candidates and determine if they are worthy of support. Normally academics with a wide background from within a discipline are assembled to make decisions.'

In many disciplines, it is difficult to develop efficient and accurate selection procedures which will admit only those students who will succeed and exclude 
those who will not. Major fields of study, motivation and academic performance are usually criteria used for selection; but such considerations can be affected on a year-to-year basis by such things as the need for more or fewer persons to fill graduate assistantships. Factors used to select fellowship winners have varied over time, although grades have been one of the consistent attributes.

Each of the national granting agencies has, over the years, developed criteria to determine which applicants would receive fellowships. In allocating fellowships, SSHRCC has established clear theoretical principles which are to be used by assessors. They are explicit in identifying academic merit as the sole criterion. In more specific terms, SSHRCC guidelines identify the excellence in past academic results, the training already acquired, the evaluation of the referee, the originality of the applicant's program of study and research, the potential contribution to the advancement of knowledge, and, where applicable, the departmental rankings of applicants. ${ }^{2}$ Thus far, however, few studies have been carried out to ascertain the application of criteria used by SSHRCC committees to select winners of fellowships. The present research will identify those factors defined as important by reviewers in the areas of sociology, communications, criminology and social work.

\section{Methods}

In the 1992-93 competition for SSHRCC fellowship program, 3,149 applications for doctoral fellowships were received. This represents nearly a ten percent increase over the number of applicants from the previous year. Out of this total, twenty-five percent of the applicants were successful, for a dollar value of $\$ 3.8$ million. Because of the large number of applications for doctoral fellowships, SSHRCC has created a number of doctoral fellowship committees which are discipline specific. For example, Committee Seven deals with applicants in the fields of Sociology, Communications, Criminology and Social Work. Other committees have been established to handle applicants from other disciplines, e.g., Education, Law, Political Science.

The evaluating committee (Committee Seven) consists of six faculty members from across Canada who were approached by SSHRCC officials to participate in the review process. All six were provided with the entire files of the 291 applicants; however, each adjudicator read and ranked only 150 files randomly chosen by SSHRCC officials. Hence, each application was ranked by three faculty. After the applications were read, each member was asked to allocate a certain percentage of the applications to each of ten categories (10 being the highest, 1 being the lowest). ${ }^{3}$ These rankings took place independently and were 
then sent to SSHRCC officials who tabulated the scores and provided a summated score of rankings for each candidate. ${ }^{4} \mathrm{~A}$ surprising consensus in rank order emerged. However, in all cases where ratings varied by more than four ranks, applicants were discussed in a follow-up conference call by all six adjudicators. Out of the nearly 300 files, fewer than ten cases revealed this kind of divergence. In short, the system seemed to work very well. The committee allocated 58 awards, reaching a success rate of twenty percent, similar to the success rate of other committees in SSHRCC. How then could such congruency emerge out of applications containing considerable data -- over ten pages long? In an attempt to identify those factors which seemed to promote this congruence, we subjected the data to statistical analysis relevant to a multiple causation model.

The sample represents a simple random sample of 114 files from a total of 291 Sociology, Communications, Social Work and Criminology applicants for SSHRCC doctoral fellowships. Information from each file was coded and subjected to statistical analysis. Letters of recommendation accompanying each file also were coded to identify positive and negative comments. Grade point averages were not computed because of the diversity of grading schemes as well as differing careers of the applicants. For example, an individual receiving her/her M.A. from a European school cannot be compared to a Canadian school with regard to grade point averages. The mode of presentation of grades by postsecondary institutions also confounds the ability to provide a summated score or any score which allows for a meaningful comparison. Nevertheless, in reviewing all 291 applications, fewer than 100 "B" grades appeared in the graduate transcripts. This reflects the uniformly high academic standards achieved by the entire cohort and suggests that GPA would be a constant, and not subject to variation.

\section{Results}

\section{Descriptive Profile}

While we report the sample statistics, we were able to determine some population attributes, e.g., gender, last school attended. The sample results reflect the population distribution very closely, thus strengthening our confidence in the sample results. For example, in our sample, $62 \%$ of the applicants were female, while in the population the percentage was $65 \%$. Other variables we were able to compare with the population revealed similar levels of congruity.

Over $80 \%$ of the respondents' last degrees were in Social Science, and $86 \%$ came from universities in Canada. The applicants varied in time since the last 
degree. While many had just completed their degree the previous year (32\%), nearly one-third of the applicants had completed their last degree between one and four years previously. An additional $16 \%$ would complete their degree in the spring of the same year they would enter the Ph.D. program. Over $92 \%$ indicated they had held at least one job during their educational career. Over half of these jobs were with an educational institution, and included such roles as teaching assistant, research assistant, sessional instructor, while other jobs revealed a wide diversity. Over half of the applicants claimed to have won at least three academic awards over their educational careers. These awards ranged from medals of distinction to dean's lists to scholarships and bursaries.

Seventy percent of the applicants claimed a scholarly publication, with nearly one-half claiming at least three publications. The most common form was a paper presentation (25\%). This was followed by an article (non-refereed) $(11 \%)$, co-edited work with professors $(16 \%)$ and refereed publications (3\%). Seven percent noted a forthcoming publication, but did not identify the venue.

Referees were asked to assess each candidate with regard to a number of attributes such as background preparation, originality, industry and all-around ability. Referees were asked to rank the applicant on seven attributes ${ }^{5}$ in one of five categories, ranging from the top two percent of students at a comparable level of study, to the lower fifty percent. Not surprising, fewer than two percent claimed "inadequate opportunity" to judge. Thus, one may conclude that each referee was familiar with the applicant's work habits, scholarly activities and potential. Well over three-quarters of the referees placed applicants in the top thirty percent, with over two-thirds placing their candidate in the top ten percent. Assessments of students by professors showed that an overwhelming number $(81 \%)$ reported only positive attributes of the applicant. For those expressing "negative" assessments, the issues focused on lack of English, lack of self-confidence, lack of methodological knowledge, and impatience. Positive assessments focused on sound theoretical basis (21\%), innovative ideas (15\%), critical thinking $(9 \%)$ and desire to learn (13\%).

\section{Model Testing}

The general model to be tested reflects a belief that several factors were responsible for a referee placing a candidate's application in the "winner's" category. Hence, we subjected our data to multivariate analysis, using the summated rank score from the three referees as the dependent variable. The final summated score (ranging from 4 to 28$)^{6}$ was left as a continuous variable and constituted our dependent variable. Independent variables initially included varied in level of measurement from nominal to interval. Specific independent variables 
included in the analysis were: first degree held, highest degree held, institution of first (and highest) degree, current university affiliation, institutional affiliation of referees, previous employment, types of jobs held, academic awards received, publications, referee appraisals, status of referee, students' rank order within a department, size of department, strengths and weaknesses identified by referees and the gender of the applicant.

Given the exploratory nature of this project and the large pool of independent variables, regressions using stepwise selection procedures were run initially to determine the best combination of variables, based on the data in this sample, to include in a final regression equation. Many stepwise regressions were run in order to try out different coding schemes for some of the variables, and to substitute variables with others that appeared to be measuring the same concept. ${ }^{7}$ Given the small sample size (114) and the list-wise deletion of mission values used in regression, weighting the entire sample by a factor of two was necessary when all the independent variables were included. The sample was unweighted once some of the variables were eliminated as a result of not appearing in any equations even when the sample was weighted. ${ }^{8}$ Once variables were chosen on the basis of an evaluation of the equations that appeared when using stepwise selection, the partial regression coefficients in a series of hierarchical models and models including interaction effects were examined, and these models were tested for significant changes in $\mathrm{R}^{2}$.

The three variables that consistently appeared in the regression equations chosen by stepwise selection and had strong positive effects on the score of the student are: the rank given the student by the department (RANKD), the referee appraisals regardless of which of the three coding schemes is used (ABILITY, OVERALL, or EVALUATE), and the acquisition of a previous graduate scholarship, grant or fellowship (AWARDSH). . The partial regression coefficients for these variables when regressed on the dependent variables are listed in Table 1. The effects for each of the referee coding schemes are presented. The results show that in two of the three cases, department ranking of the student has a slightly stronger positive effect than referee appraisal, and that both of these have stronger effects than achieved awards. A significant among of variance is explained by these equations and, in all three cases, the increase in $R^{2}$ from the bivariate to this multivariate additive equation was significant at the .05 level for each variable added.

The dummy variable measuring publication of an article or review (compared to those applicants who had no publications or had only paper presentations), PUBLICAR, also showed up in several equations chosen by stepwise 
Table 1

Partial Standardized and Unstandardized Regression Coefficients for the First Additive Model using Three Different Coding Schemes for Referee Appraisals

\begin{tabular}{|c|c|c|c|c|c|c|c|c|c|}
\hline \multirow[b]{2}{*}{ Variable } & \multicolumn{3}{|c|}{ Ability } & \multicolumn{3}{|c|}{ Overall } & \multicolumn{3}{|c|}{ Evaluate } \\
\hline & $\underline{\mathbf{b}}$ & SEb & Beta & $\underline{b}$ & $\underline{S E b}$ & Beta & $\underline{\mathbf{b}}$ & SEb & Beta \\
\hline Awardsch & 3.396 & $1.11 \mathrm{~s}$ & .198 & 4.679 & 1.075 & .273 & 2.498 & 1.036 & .145 \\
\hline Rankd & .684 & .10 & .444 & .712 & .106 & .456 & .546 & .094 & .383 \\
\hline $\begin{array}{l}\text { Ability or } \\
\text { Overall or } \\
\text { Evaluate }\end{array}$ & 1.961 & .32 & .434 & 3.626 & .605 & .404 & .477 & .057 & .567 \\
\hline Intercept & & $23.88^{\circ}$ & & & 11.472 & & & 39.012 & \\
\hline & $\mathrm{N}=8$ & $\mathbf{R}^{2}$ & $677^{*}$ & $N=9$ & & $.671^{*}$ & $N=$ & $\mathbf{R}$ & $=.771 *$ \\
\hline
\end{tabular}

${ }^{*} \mathrm{~F}$ value is significant at the .05 level

selection, as did the variable measuring the number of students applying from a department, APPLYD. APPLYD gives an indication of the size of the department from which the applicants come. This variable was dummy-coded (such that 1 indicates a high number of students applying and thus, presumably, larger departments), in order more clearly to interpret interaction effects later. PUBLICAR and APPLYD were entered into the regression equation in that order, along with the previous variables, to create a second and expanded additive equation, the coefficients for which are listed in Table 2.

Publication of an article when compared to not publishing at all, or only presenting a paper, had a statistically significant positive effect on the final score of the applicant, regardless of how referee appraisals were coded. The additional variance explained by PUBLICAR is significant at the .05 level, while the incremental variance explained by APPLYD was not significant at the .05 level.

It was hypothesized that an interaction effect involving the department rank of the student and the number of students applying may exist. Table 3 lists the results obtained when this interaction effect is added to the equation. The increase in $\mathrm{R}^{2}$ from the main effects model to the model containing interaction was statistically significant at the .05 level, indicating that an interaction is indeed present. Contrary to expectations, the nature of this effect is such that 
Table 2

Partial Standardized and Unstandardized Regression Coefficients for the Second Additive Model using Three Different Coding Schemes for Referee Appraisals

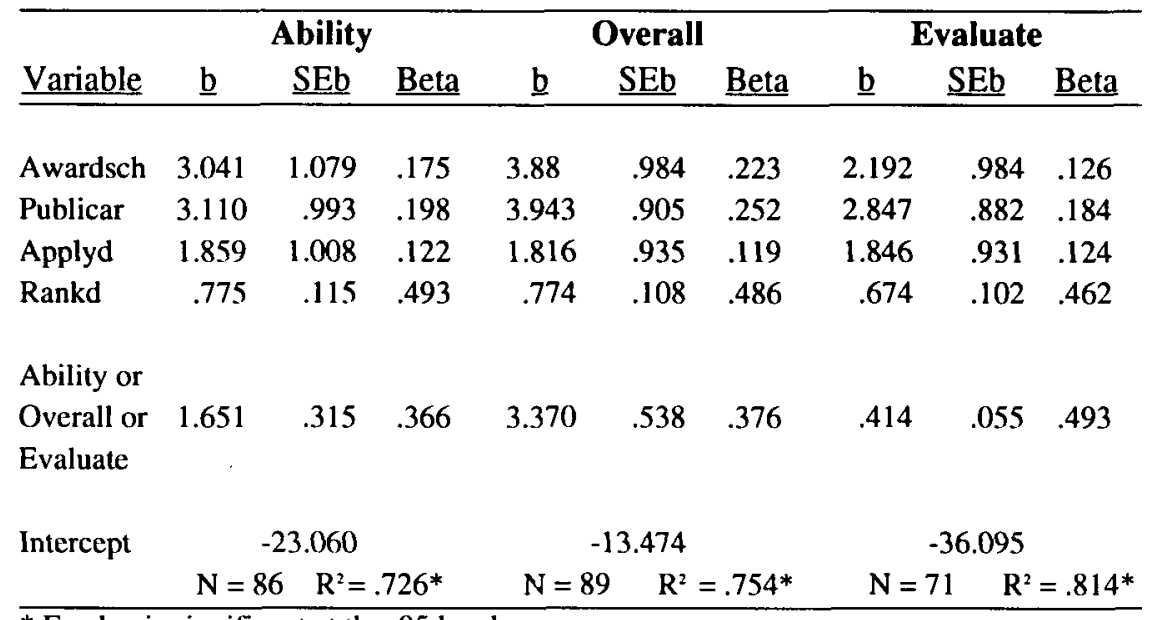

${ }^{*} \mathrm{~F}$ value is significant at the .05 level

Table 3

Partial Unstandardized Regression Coefficients for the Second Additive Model with One Interaction Effect Included. Using Three Coding Schemes for Referee Appraisals

\begin{tabular}{|c|c|c|c|c|c|c|}
\hline \multirow[b]{2}{*}{ Variable } & \multicolumn{2}{|c|}{ Ability } & \multicolumn{2}{|c|}{ Overall } & \multicolumn{2}{|c|}{ Evaluate } \\
\hline & $\underline{\mathrm{b}}$ & $\underline{\mathrm{SEb}}$ & $\underline{\mathrm{b}}$ & $\underline{\mathrm{SEb}}$ & $\underline{\mathbf{b}}$ & $\underline{\mathrm{SEb}}$ \\
\hline Awardsch & 3.739 & 1.013 & 4.405 & .903 & 2.775 & .883 \\
\hline Publicar & 2.060 & .956 & 2.898 & .858 & 1.774 & .820 \\
\hline Applyd & 21.735 & 5.235 & 21.347 & 4.616 & 23.215 & 5.011 \\
\hline Rankd & 1.737 & .271 & 1.708 & .238 & 1.711 & .257 \\
\hline $\begin{array}{l}\text { Ability or } \\
\text { Overall or } \\
\text { Evaluate }\end{array}$ & 1.336 & .302 & 2.869 & .503 & .370 & .050 \\
\hline App $\times$ rank & -1.070 & .278 & -1.057 & .245 & -1.127 & .261 \\
\hline Intercept & & 250 & -29 . & 125 & & 16 \\
\hline & $N=86$ & $\mathrm{R}^{2}=.770$ & $N=89$ & $\mathrm{R}^{2}=.799 *$ & $N=71$ & $\mathrm{R}^{2}=.856^{*}$ \\
\hline
\end{tabular}


influence of rank is weaker for students from large departments than it is for students from small departments. However, a closer examination of the intercepts and slopes of the individual equations for large and small departments reveals that when rank is average (approximately 5th from the top), students from large departments will have a distinct advantage over students from small departments. As ranks become higher, the size of the department becomes a less important distinguisher, such that the top ranking students from small schools are no longer disadvantaged when compared to the top ranking students from large schools.

Further equations created in order to test the effects of variables that appeared more occasionally in the stepwise regressions revealed that gender did not have a significant direct effect on final score of the applicant. There did appear to be some interaction on the basis of sex, however, especially in the case of sex and institution where the highest degree was obtained. For males, graduation with a Master's degree from an institution in Ontario or Quebec plays a more important role in increasing the final score than it does for women. There also is limited evidence to suggest that more mature students who graduated from university some time ago and entered the labour force (outside the academy) were viewed more favourably than those without work experience. These students are, however, also likely to have published more extensively, and further analyses of these effects needs to be undertaken.

\section{Conclusion}

Results of this study represent an exploratory analysis of the criteria used by one SSHRCC committee in selecting the winners of doctoral fellowships. A high degree of unanimity appeared within this committee when ranking applicants; and, of the criteria used to achieve this, four factors stand out. Both the referee appraisals and the rank given the student by a department are clearly instrumental in determining the final score for the applicant. Publication of an article or review and the acquisition of a graduate of a graduate scholarship, fellowship or grant appear to play a lesser, but nevertheless significant role in obtaining a final higher score. As expected, there is also an interaction effect between the number of students applying from a department and the rank given the student by the department. Tentative conclusions drawn regarding interaction effects on the basis of sex, and the advantage accorded students who obtained a Master's degree some time ago and spent time working outside of academic institutions, merit investigation in future studies. 


\section{Implications}

The results of the present research need to be juxtapositioned with those from other committees in SSHRCC, NSERC and MRC committees. First, if similar procedures are undertaken, do these results match? Second, if other procedures are employed in the granting of fellowships, how do these results compare with alternative strategies? In short, a comparative, longitudinal study needs to be undertaken to address the issue fully. Obtaining a fellowship is becoming increasingly competitive as the number of fellowships decreases and the number of applicants increases. As such, the basis upon which decisions are made must be subject to a reality check.

Previous awards are an important factor and generally emerge out of undergraduate performance. As O'Brecht and Pihl (1991) and O'Brecht (1989) have pointed out, however, grades have little predictive value of post-doctoral activities (e.g., publications, contributions to the field). In the end, they conclude, high grades lead to awards which lead to more awards which may not lead to an impact on the discipline. Likewise, the above authors note that sponsors' assessments of applicants are poor predictors of past doctoral activities. In short, referees are prone to support "their" students out of loyalty rather than objective assessment.

The results obtained show that without explicitly stating their criteria for "academic merit," a diverse group of scholars within a discipline share similar values. Two of the most important predictors, however, seem to have little "predictive validity." This suggest that new criteria should be taken into consideration when evaluating the potential of applicants. O'Brecht et al. (1989) suggest that more weight needs to be given to the department (or unit) in which the applicant will be resident. More information should also be obtained about the supervisor, as these two factors seem to be highly correlated with post-doctoral activities. In the end, academics are able to achieve consensus in assessing applications. The predictive validity of such assessments, however, is not particularly useful. Thus, granting agencies need to re-assess the criteria used for determining recipients of fellowship awards.

\section{Notes}

1 The specific selection strategy vary among disciplines.

2 The Council does not assign weights to any of the above criteria.

3 Fellowship applications are marked on a ten-point scale. In the end, reviewers are asked to distribute the marks in a normal distribution so that $2 \%$ receive a score of 1 (low), $5 \%$ a $2,1 \%$ a $3,14 \%$ a $4,19 \%$ a $5,19 \%$ a 6 , ctc. 
4 The averages for candidates were calculated, and the following analysis was computed using means rather than summated ranks. The results show little difference from the data in Tables 1 to 3 .

5 Background preparation, originality, ability at research and potential, industry judgment, oral and written communication, all around ability.

6 A score of three could be attained if all three referees place the candidates in category 1; while a score of 30 would be obtained if all three referees placed the candidate in category 10 . The actual distribution shows that the highest score obtained by a candidate was 28 , while the lowest was 4 .

7 Rather than choosing between the coding schemes for referee appraisals, we have reported findings for all three coding schemes. Different concepts are being measured in each coding scheme, and each has different weaknesses. For example, the variable EVALUATE measures the combined additive effect of all seven of the appraisal items, but suffers from a high number of missing values; ABILITY measures only one category -- the referee's appraisal of the applicant's "all-round ability;" and OVERALL, the lowest overall score for an applicant on the appraisal items, measures the importance of consistently high scores on all items. The final regression equation does differ somewhat for each coding scheme.

8 Weighting the sample results in inflated $T$ values. One of the effects of doing this with stepwise regression is that the equations chosen have a greater number of variables in them than they would have otherwise had. Thus, the sample was unweighted as soon as possible, and further stepwise regressions and the final regression equations reported were run on the original (unweighted) sample.

9 Rank of the student and referee appraisals were continuous variables and AWARDSH was a dichotomous variable coded 1 if the applicant had received previous graduate awards as outlined in the text (excluding assistantships) and 0 if the applicant had received lesser awards or no awards at all.

\section{References}

Abu-laban, B., \& Rule, B. (1988). The human sciences. Edmonton: The University of Alberta Press.

Gumport, P. (1990). Transformations in American graduate education and research. Educational Policy, 4, 313-326.

Khashan, Hilal. (1992). How grantecs relate to grantor. Research in Higher Education, $33,263-273$.

Macdonald, J. (1966). The topmost layer: An examination of the purposes and functions of American graduate schools. Comparative Education, 2, 151-166.

Norbert, L., McDowell, R., \& Goulet, D. (1991). Profile of higher education in Canada. Ottawa: Education Support Branch, Department of Secretary of State.

O'Brecht, M., Pihl, R., \& Bois, P. (1989). Criteria for granting research training awards to graduate students. Research in Higher Education, 30(6), 647-664.

O'Brecht, M., \& Pihl, R. (1991). Granting agency criteria for awarding graduate research scholarships. The Canadian Journal of Higher Education, 21(3), 47-58. 
106 G. Wall \& J.S. Frideres

Pavalko, R. (Ed.). (1968). Sociology of education. Itasca, Illinois: F.E. Peacock Publishers, Inc.

Segal, B. (Chair). (1992). AUCC task force on the report of the Commission of Inquiry on Canadian university education. Ottawa.

Trent, J. (Ed.). (1984). Social science research in Canada: Stagnation or regeneration. Ottawa: Science council of Canada. 